\title{
Optimizing the diagnosis of pelvic lymph node metastasis in bladder cancer using computed tomography and magnetic resonance imaging
}

\author{
Thomas B. L. Lam*
}

Bladder cancer (BCa) is one of the most common malignant urogenital tumors in the world, and is especially common in China [1]. An important component of $\mathrm{BCa}$ staging is the determination of pelvic lymph node status, which provides valuable prognostic information and influences treatment decisions [2]. Cross-sectional imaging techniques such as computed tomography (CT) and magnetic resonance imaging (MRI) have proven to be useful for detecting malignant involvement of the pelvic lymph nodes. Both methods rely on morphological criteria, specifically, size and shape, as a predictor of lymph node metastasis [3]. Over the past decade, tremendous advances in CT and MRI technology, including the introduction of diffusion-weighted and ultra-small, superparamagnetic-particle, iron-oxide-enhanced MRI techniques, have greatly improved imaging resolution, thus readily revealing lymph nodes with diameters as small as $3.0 \mathrm{~mm}$. In addition, the small intestine can be examined without inflation and small veins can be easily distinguished from lymph nodes [4, 5]. However, a clear consensus regarding the new criteria for imaging-based lymph node evaluation is lacking, and the two modalities must once again be assessed for their ability to detect metastatic lymph nodes. In a study recently published in the Chinese Journal of Cancer, titled "Computed tomography and magnetic resonance imaging evaluation of pelvic lymph node metastasis in bladder cancer," Li et al. [6] analyzed the diagnostic accuracy of CT and MRI. Using pelvic lymph node dissection and histopathology as the reference standard, they were able to establish optimal diagnostic criteria.

*Correspondence: thomasbllam@abdn.ac.uk

Academic Urology Unit, Division of Applied Health Sciences, University of Aberdeen, Aberdeen AB25 2ZD, Scotland, UK
In their study, the authors retrospectively examined the imaging characteristics of $191 \mathrm{BCa}$ patients who underwent radical cystectomy. Data on the size, shape, density, and diffusion of the lymph nodes on CT and/or MRI were obtained and analyzed. Lymph node metastasis was pathologically diagnosed in 47/191 (24.6\%) patients. Metastases were detected in 184 of the 3317 resected lymph nodes, mainly in those of the perivesicular, external iliac, internal iliac, and obturator regions. Among the imagingdetectable lymph nodes, 51/82 (62.2\%) were confirmed to be positive for metastasis. The detection rate of metastatic nodes increased as the tumor stage increased. Lymph nodes with a short-axis diameter of $<3.0 \mathrm{~mm}$ were rarely seen on CT and/or MRI. The receiver operating characteristic (ROC) curve analysis showed that a short diameter of $6.8 \mathrm{~mm}$ was the optimal threshold for the diagnosis of metastatic lymph nodes, based on an area under the ROC curve of 0.815 , a sensitivity of $83.0 \%$, a specificity of $64.3 \%$, and a Youden index of $47.3 \%$. Imaging signs such as the fatty hilum of the lymph node and a short/long-axis diameter ratio $\leq 0.4$ were usually characteristic of non-metastatic lymph nodes, while spiculated margins and necrosis were commonly observed in metastatic lymph nodes.

Size is a well-established and important index for detecting malignancy in the pelvic lymph nodes. In general, a smaller threshold values indicates a higher sensitivity and lower specificity; and a larger threshold a lower sensitivity and higher specificity. Although, by convention, a short-axis lymph-node diameter of $10 \mathrm{~mm}$ is considered the threshold value for malignancy on both CT and MRI [7, 8], several recent studies demonstrated that a cutoff value of $10 \mathrm{~mm}$ was not appropriate $[9,10]$. The optimal cutoff value of $6.8 \mathrm{~mm}$ determined by $\mathrm{Li}$ et al. [6] has the potential to modify current diagnostic and 
treatment algorithms for $\mathrm{BCa}$. In addition to lymph node size, several imaging characteristics were identified as indicative of benign changes in the lymph nodes, such as a short/long-axis lymph node diameter ratio of $\leq 0.4$ and the presence of a fatty hilum. Other characteristics correlated with lymph node metastasis, such as spiculate or obscure margin and necrosis.

The limitations of the study were the relatively small number of patients enrolled $(n=191)$, the high attrition rate $(<80 \%$ of patients who underwent standard pelvic lymphadenectomy were enrolled), and the retrospective study design. Nevertheless, the findings will contribute to the discussion on the criteria for the diagnosis of metastatic lymph nodes in $\mathrm{BCa}$ and should encourage future prospective studies to validate them.

\section{Authors' contributions}

The author read and approved the final manuscript.

\section{Acknowledgements}

Not applicable.

\section{Competing interests}

The author declares no competing interests.

Availability of data and materials

Not applicable.

\section{Consent for publication}

Not applicable.

Ethics approval and consent to participate

Not applicable.

\section{Funding}

Not applicable.

Received: 5 March 2018 Accepted: 7 March 2018

Published online: 12 March 2018
References

1. Siegel RL, Miller KD, Jemal A. Cancer statistics, 2016. CA Cancer J Clin. 2016;66(1):7-30.

2. Leissner J, Ghoneim MA, Abol-Enein H, Thüroff JW, Franzaring L, Fisch $M$, et al. Extended radical lymphadenectomy in patients with urothelial bladder cancer: results of a prospective multicenter study. J Urol. 2004;171(1):139-44.

3. Saokar A, Islam T, Jantsch M, Saksena MA, Hahn PF, Harisinghani MG. Detection of lymph nodes in pelvic malignancies with computed tomography and magnetic resonance imaging. Clin Imaging. 2010;34(5):361-6.

4. Thoeny HC, Froehlich JM, Triantafyllou M, Huesler J, Bains LJ, Vermathen $\mathrm{P}$, et al. Metastases in normal-sized pelvic lymph nodes: detection with diffusion-weighted MR imaging. Radiology. 2014;273(1):125-35.

5. Triantafyllou M, Studer UE, Birkhäuser FD, Fleischmann A, Bains LJ, Petralia $\mathrm{G}$, et al. Ultrasmall superparamagnetic particles of iron oxide allow for the detection of metastases in normal sized pelvic lymph nodes of patients with bladder and/or prostate cancer. Eur J Cancer. 2013;49(3):616-24.

6. Li Y, Diao F, Shi S, Li K, Zhu W, Wu S, et al. Computed tomography and magnetic resonance imaging evaluation of pelvic lymph node metastasis in bladder cancer. Chin J Cancer. 2018;37:3.

7. Anzai Y, Piccoli CW, Outwater EK, Stanford W, Bluemke DA, Nurenberg P, et al. Evaluation of neck and body metastases to nodes with ferumoxtran 10-enhanced mr imaging: phase III safety and efficacy study. Radiology. 2003;228(3):777-88.

8. Jager GJ, Barentsz JO, Oosterhof GO, Witjes JA, Ruijs SJ. Pelvic adenopathy in prostatic and urinary bladder carcinoma: MR imaging with a threedimensional ti-weighted magnetization-prepared-rapid gradient-echo sequence. AJR Am J Roentgenol. 1996;167(6):1503-7.

9. Koh DM, George C, Temple L, Collins DJ, Toomey P, Raja A, et al. Diagnostic accuracy of nodal enhancement pattern of rectal cancer at MRI enhanced with ultrasmall superparamagnetic iron oxide: findings in pathologically matched mesorectal lymph nodes. AJR Am J Roentgenol. 2010;194(6):W505-13.

10. Barentsz JO, Engelbrecht MR, Witjes JA, de la Rosette JJ, van der Graaf M. MR imaging of the male pelvis. Eur Radiol. 1999;9(9):1722-36.
Submit your next manuscript to BioMed Central and we will help you at every step:

- We accept pre-submission inquiries

- Our selector tool helps you to find the most relevant journal

- We provide round the clock customer support

- Convenient online submission

- Thorough peer review

- Inclusion in PubMed and all major indexing services

- Maximum visibility for your research

Submit your manuscript at www.biomedcentral.com/submit
C Biomed Central 